\title{
Late-Onset Rash from Irbesartan: An Immunological Reaction
}

\author{
Bárbara Kong Cardoso, Marta Martins, Sofia Martins Farinha, Regina Viseu, Elza Tomaz, Filipe Inácio \\ Centro Hospitalar de Setúbal, Serviço de Imunoalergologia, Setúbal, Portugal
}

Doi: 10.12890/2019_001128 - European Journal of Case Reports in Internal Medicine - ๔ EFIM 2019

Received: 24/04/2019

Accepted: 08/05/2019

Published: 19/06/2019

How to cite this article: Kong Cardoso B, Martins M, Martins Farinha S, Viseu R, Tomaz E, Inácio F. Late-onset rash from irbesartan: an immunological reaction. EJCRIM 2019;6: doi:10.12890/2019_001128.

Conflicts of Interests: The Authors declare that there are no competing interests.

This article is licensed under a Commons Attribution Non-Commercial 4.0 License

\section{ABSTRACT}

Cutaneous delayed reactions to antihypertensive drugs have been described in a limited number of case reports but the mechanisms remain mostly unknown. We report the case of a 60-year-old female patient with a 3-week history of an itchy erythematous maculopapular eruption. Although the patient was polymedicated, irbesartan was the most likely culprit. Patch tests and a lymphocyte transformation test to irbesartan were both positive, which was useful for diagnosis and suggested an immunological reaction. No new lesions appeared after irbesartan was stopped or after the introduction of candesartan. Despite its similar chemical structure, candesartan may be tried in patients allergic to irbesartan.

\section{LEARNING POINTS}

- Irbesartan can induce immunological cell-mediated skin reactions.

- Allergy to irbesartan does not imply a class allergy.

- Patch tests and a lymphocyte transformation test were useful in the diagnosis of irbesartan allergy.

\section{KEYWORDS}

Irbesartan allergy, maculopapular rash, patch tests, lymphocyte transformation test, drug reaction

\section{INTRODUCTION}

Irbesartan is an antihypertensive drug and a class $C$ angiotensin II receptor blocker (ARB). It is prescribed for controlling hypertension, as well as for treating heart failure and preventing kidney failure in diabetic and hypertensive patients. Cutaneous side effects to ARB are uncommon ${ }^{[1]}$. Some have been described, but the mechanisms remain poorly defined in most cases. We describe an exanthematous reaction induced by irbesartan intake through a previously documented immunological mechanism.

\section{CASE DESCRIPTION}

A 60-year-old female patient was referred to our clinic with a 3-week history of an itchy erythematous maculopapular eruption affecting the torso (thorax and abdomen) and proximal parts of the upper and lower limbs, with lesions resolving with hyperpigmentation (Fig. 1).

The patient's current medications were atorvastatin, irbesartan, chlordiazepoxide, levothyroxine, estradiol patch, olanzapine and paroxetine. All but irbesartan and paroxetine had been taken for several years. Irbesartan $150 \mathrm{mg}$ daily had been introduced approximately 2 months before the exanthematous rash began and paroxetine had been introduced after the symptoms had appeared. There was no history of any infectious disease.

Histopathological examination of the lesions showed a predominantly lymphocytic infiltrate of the dermis with some eosinophils, compatible with a drug reaction. Allergy work-up included patch tests with irbesartan and candesartan ( $5 \%$ in petrolatum; the latter tested as a possible alternative). A lymphocyte transformation test (LTT) with irbesartan was also performed. 
The patch test with irbesartan was positive at 48 and 96 hours, while candesartan was negative. The LTT to irbesartan (100 $\mu \mathrm{g} / \mathrm{ml}) \mathrm{was}$ positive, showing a stimulation index of 6.3. Irbesartan was switched to diltiazem and new lesions stopped appearing.

Based on clinical and histological findings and the results of patch tests and the LTT, a delayed allergic drug reaction to irbesartan was diagnosed.

Three months later candesartan was introduced into the patient's drug regimen, with no skin reaction after 3 months.

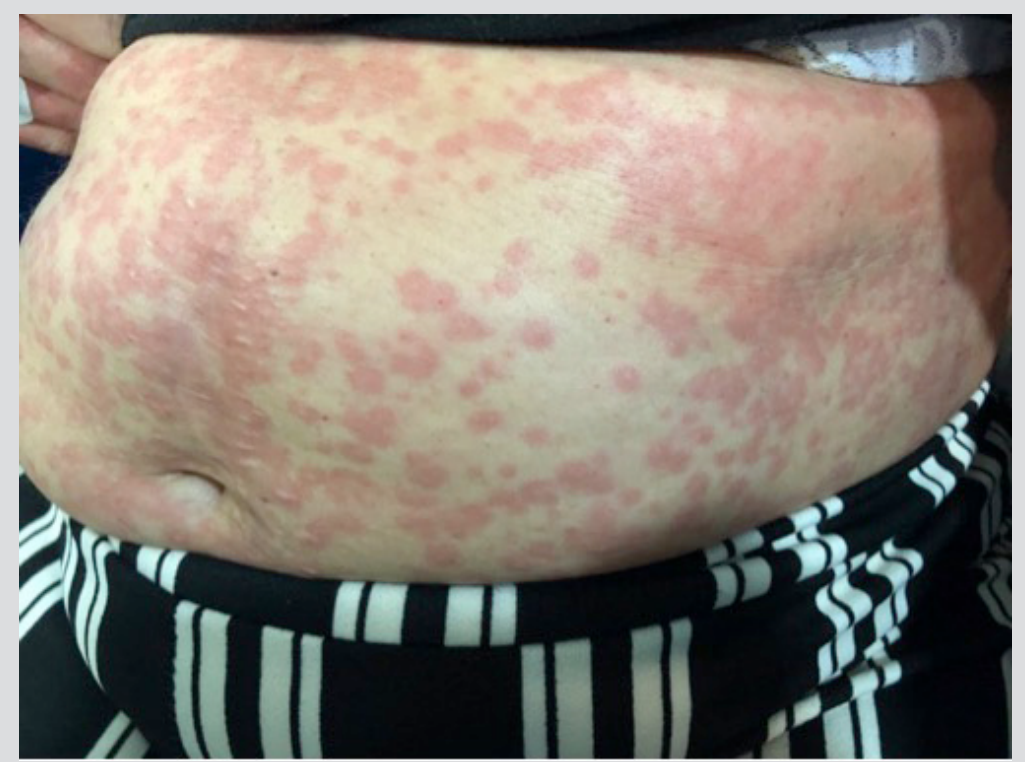

Figure 1. Erythematous maculopapular eruption affecting the torso

\section{DISCUSSION}

There are few reports of skin reactions induced by ARBs, with losartan and valsartan being the most frequent culprits ${ }^{[1]}$. Two cases due to irbesartan have been described in the literature: one case of multiform erythema with a positive LTT $^{[2]}$ and one lichenoid eruption with a positive patch test ${ }^{[3]}$. Vena et al. described a series of eczematoid reactions to angiotensin-converting enzyme inhibitors or ARBs (irbesartan in two cases $)^{[4]}$. The authors attributed the reactions to a pharmacological mechanism related to interference of the kallikrein-kinin system and elevation of circulating and cutaneous proinflammatory bradykinin, since ARBs can increase bradykinin levels in hypertensive subjects ${ }^{[5]}$. One case of irbesartan-induced maculopapular exanthema was described by Gambini et al. ${ }^{[6]}$, presenting as an acute and febrile reaction 5 days after the patient initiated irbesartan. In this case, biopsy showed an interface dermatitis characterized by a predominant upper dermal lymphocytic infiltration, similar to our patient, but no other studies were performed and the mechanism was considered unknown. In our case, the exanthema appeared later, 2 months after irbesartan introduction, and there were no constitutional symptoms. It was clear that an immunological mechanism was involved, so it was classified as an allergic reaction.

Irbesartan and candesartan are benzimidazole derivatives, both having a biphenyl-tetrazole moiety and a substituted imidazole core. Despite the similarity of their chemical structures, cross-reaction did not occur in our patient, with candesartan proving to be a safe alternative.

\section{REFERENCES}

1. Ozturk G, Turk BG, Senturk B, Turkmen M, Kandiloglu G. Exanthematous drug eruption due to valsartan. Cutan Ocul Toxicol 2012;31(4):335-337.

2. Constable S, Farrell J, Naisbitt D, King C, Leonard N, Pirmohamed M. Systemic illness with skin eruption, fever and positive lymphocyte transformation test in a patient on irbesartan. Br J Dermatol 2006;155(2):491-493.

3. Pfab F, Athanasiadis GI, Kollmar A, Ring J, Ollert M. Lichenoid drug eruption due to an antihypertonic drug containing irbesartan and hydrochlorothiazide. Allergy 2006;61(6):786-787.

4. Vena GA, Cassano N, Coco V, De Simone C. Eczematous reactions due to angiotensin-converting enzyme inhibitors or angiotensin II receptor blockers. Immunopharmacol Immunotoxicol 2013;35(3):447-450.

5. Campbell DJ, Krum H, Esler MD. Losartan increases bradykinin levels in hypertensive humans. Circulation 2005;111(3):315-320.

6. Gambini D, Sala F, Gianotti R, Cusini M. Exanthematous reaction to irbesartan. Eur Acad Dermatol Venereol 2003;17:472-473. 
European Journal

of Case Reports in

Internal Medicine 